CLINICAL CASES-SHORT REPORTS AND COMMENTS

\title{
I
}

A CASE OF PEMPHIGUS VEGETANS, A DERMATOSIS WHICH MAY BE MISTAKEN FOR SYPHILIS

By L. W. HARRISON, D.S.O., M.B., F.R.C.P.E.

THE first number of this Journal contained an article by Dr. H. C. Semon on "Skin Affections commonly

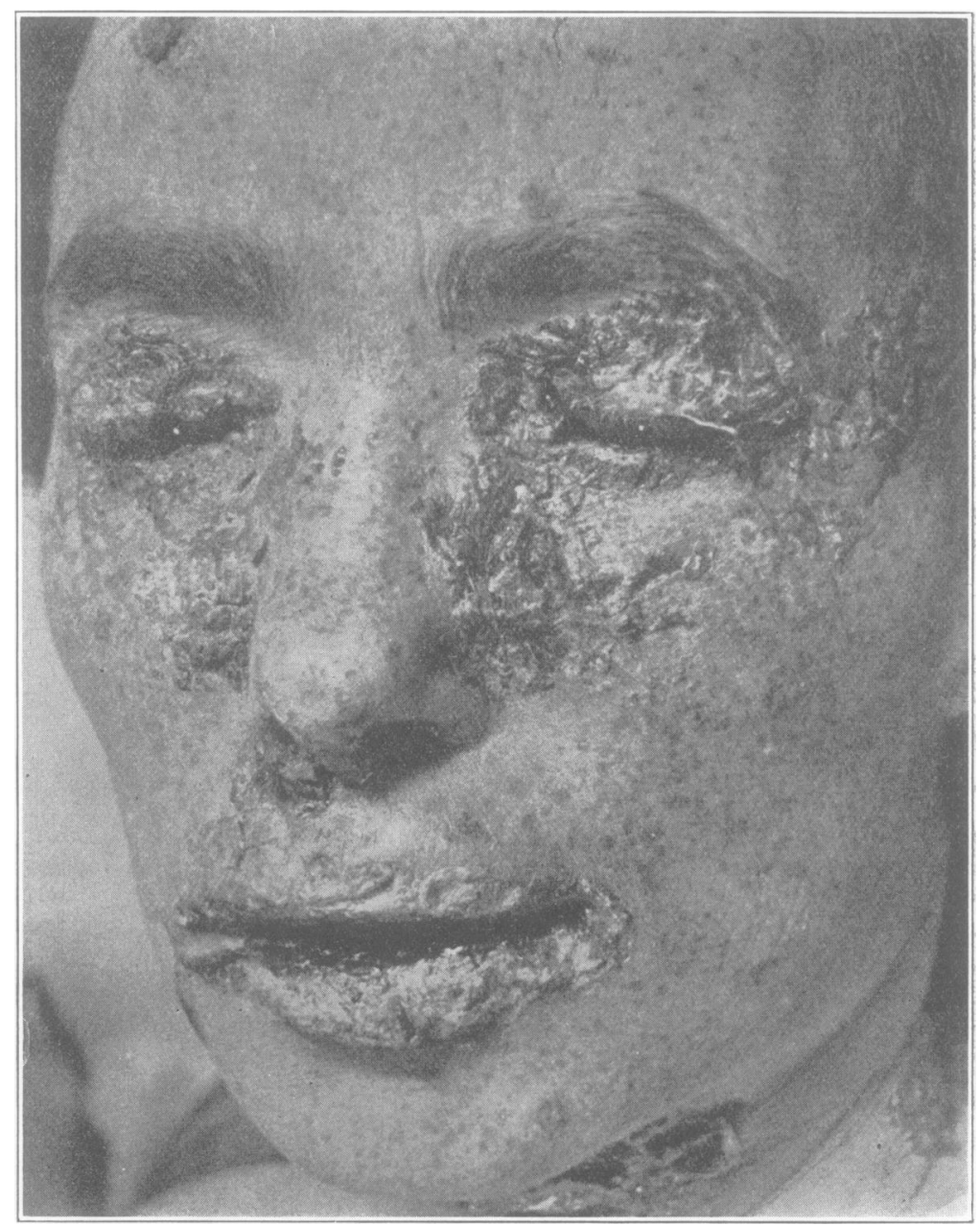

FIG. I.

76 


\section{A CASE OF PEMPHIGUS VEGETANS}

mistaken for Syphilis." Possibly the case of Pemphigus vegetans, which is illustrated by Figs. I to 7, may usefully supplement that article, since this dermatosis has some

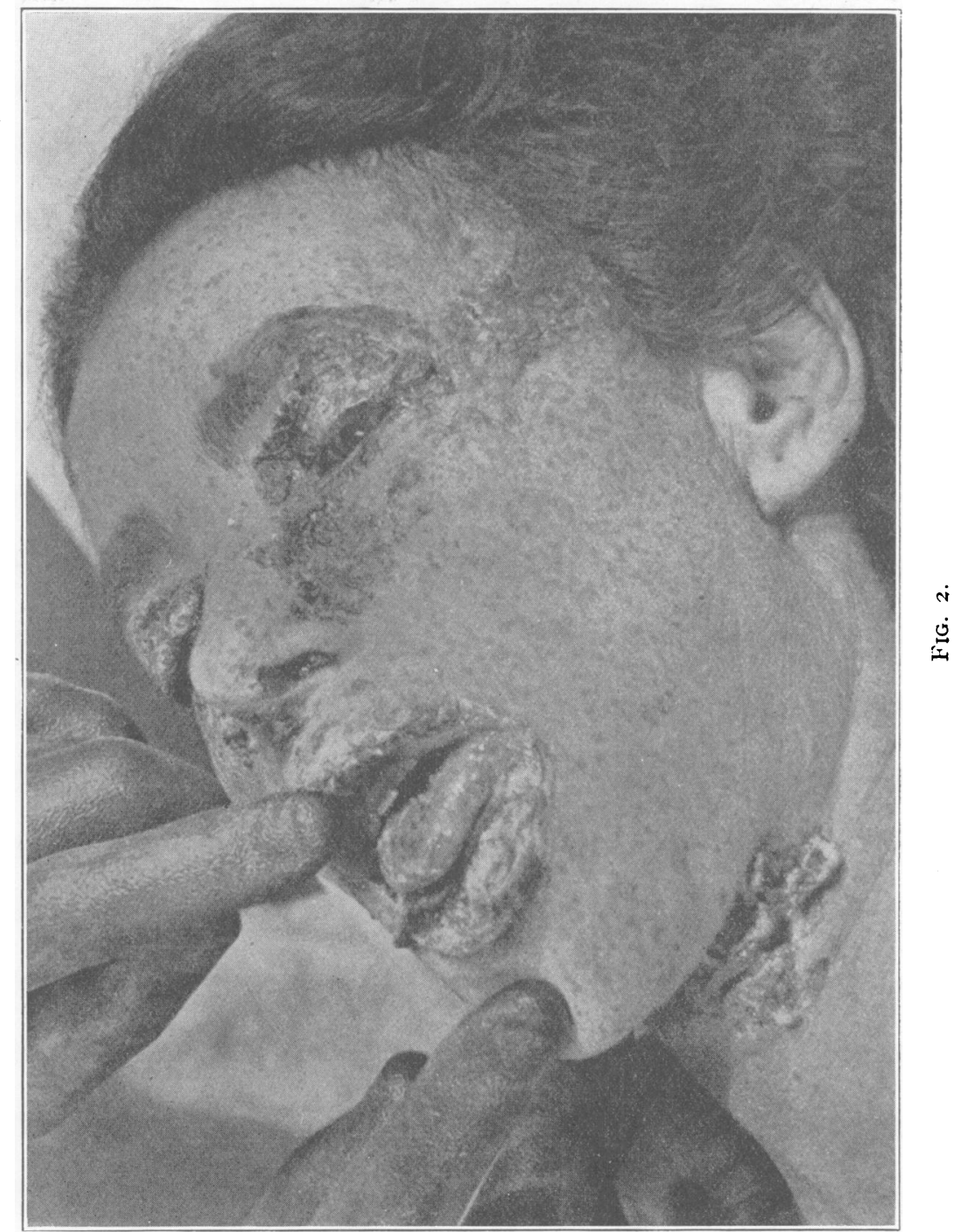

resemblance to a syphilide and (possibly, also, on account of its rarity) may be mistaken for such. At any rate, the two cases which have come to my notice were referred to me in the belief that the condition was syphilitic. In the case illustrated by the accompanying plates the 


\section{BRITISH JOURNAL OF VENEREAL DISEASES}

patient, a married Jewess, æt. thirty-nine, had six weeks previously given birth to a child who was believed to bc healthy.

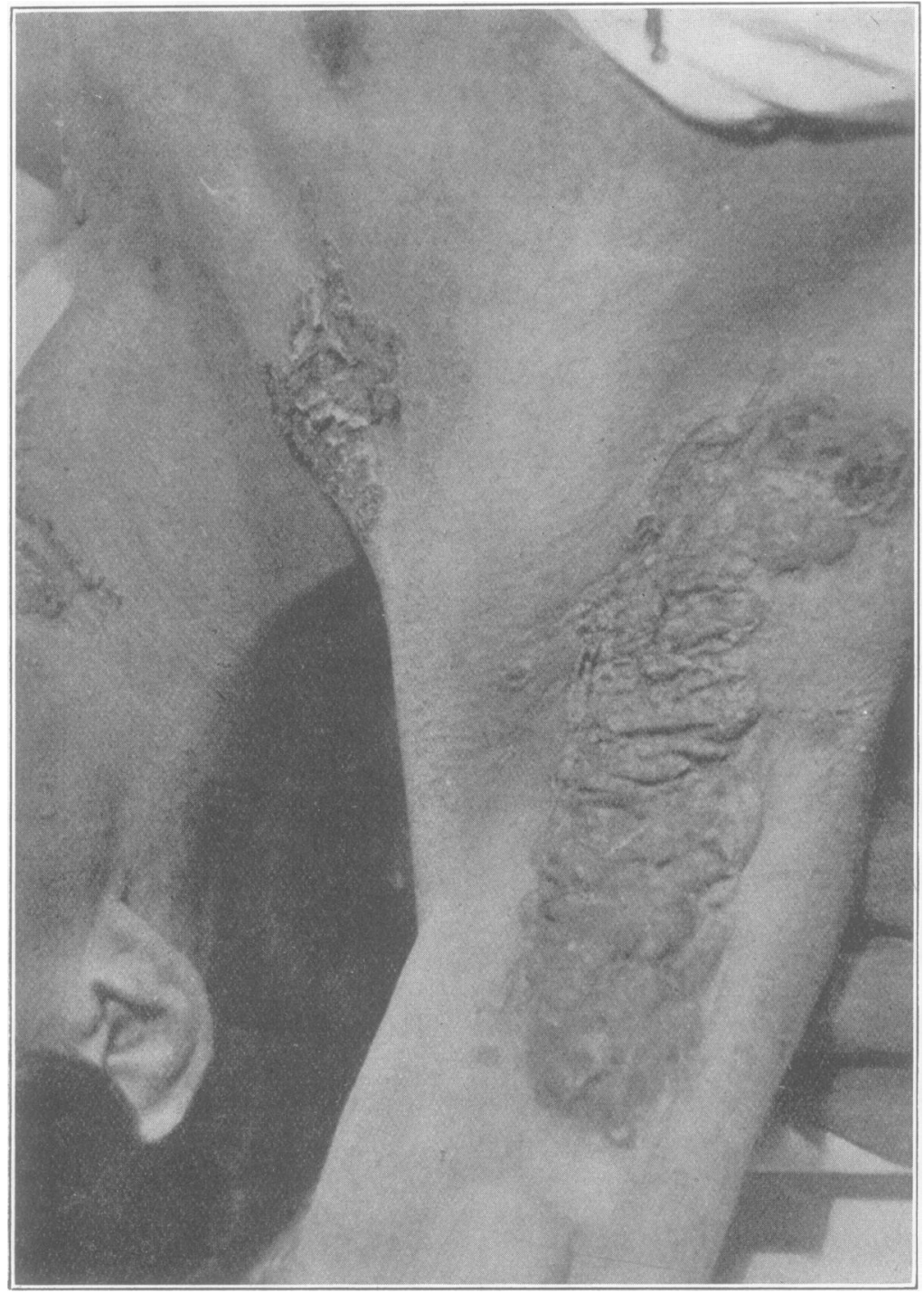

Shortly after the parturition a lesion commenced on the left eyelid and spread gradually until the condition at the time of the patient's admission to my ward in St. Thomas's Hospital was as illustrated. There were no lesions lower than the umbilicus. The serum reactions 


\section{A CASE OF PEMPHIGUS VEGETANS}

were negative. The crusts on the face, as illustrated in Fig. I, might pass for those of an echthymatous syphilide, and this impression might be strengthened by the lesions

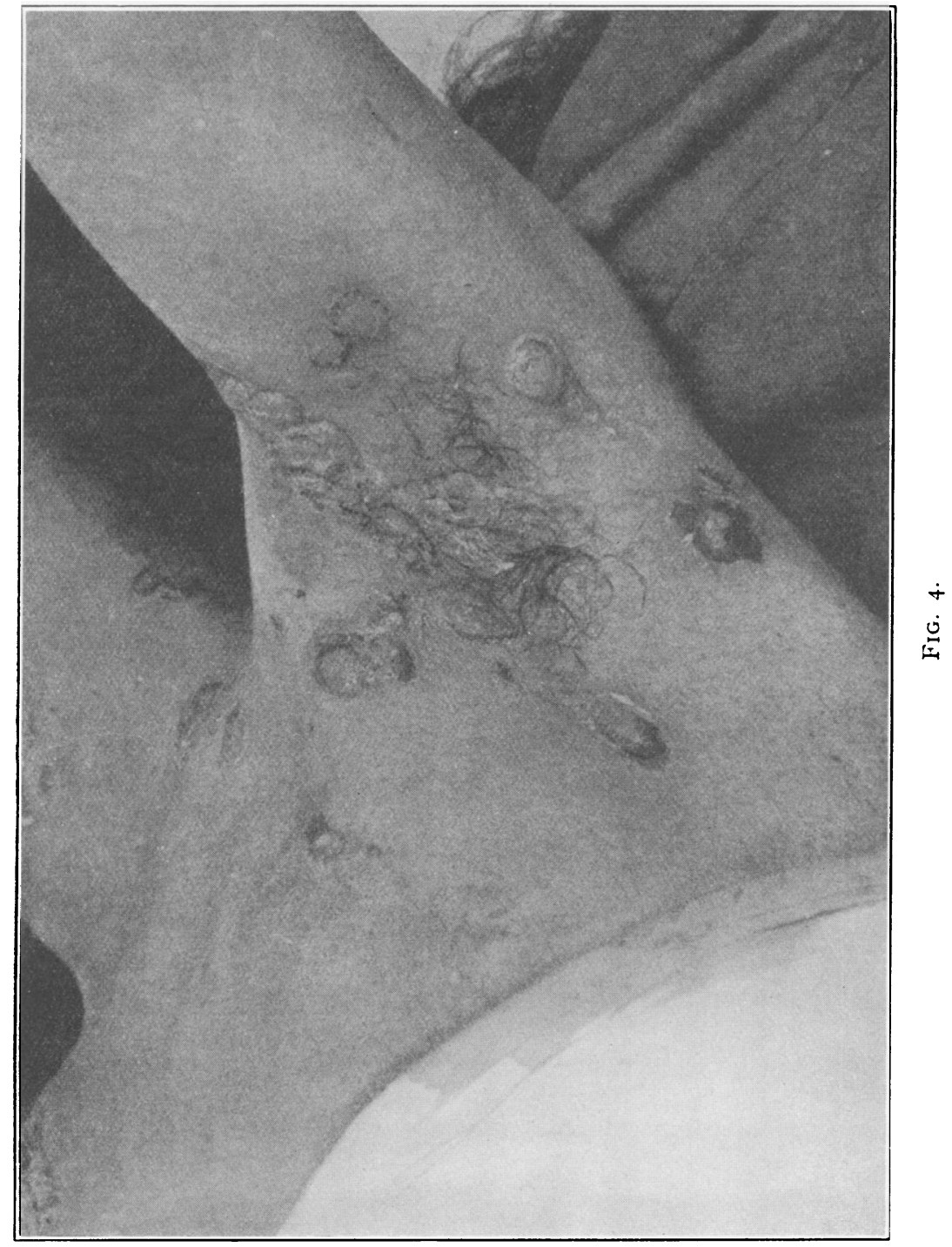

on the back which are shown in Fig. 5, since, before being powdered, these were black, limpet-like crusts resembling rupia rather closely.

The tongue and mucous surfaces of the lips (Fig. 2) were occupied by sores somewhat like mucous patches, 


\section{BRITISH JOURNAL OF VENEREAL DISEASES}

and it will be agreed that the flat warts in the axillæ, illustrated by Figs. 3 and 4 , are very good imitations of condylomata. The diagnosis in this case was not difficult

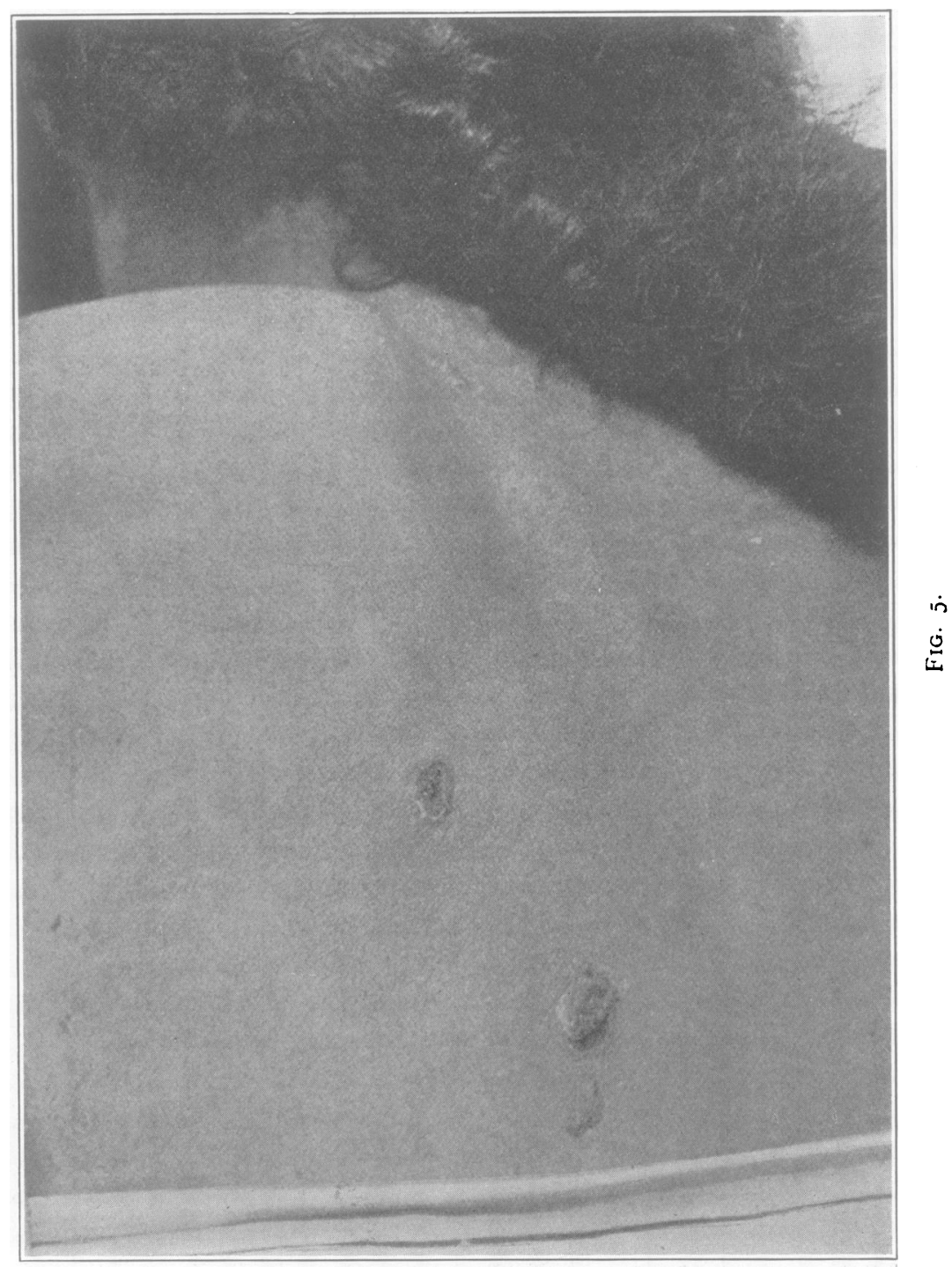

as serum was oozing from the lesions on the face and trunk much more freely than is customary with syphilides in these situations, and the bullæ on the fingers, illustrated in Figs. 6 and 7, confirmed the diagnosis of Pemphigus vegetans. 


\section{A CASE OF PEMPHIGUS VEGETANS}

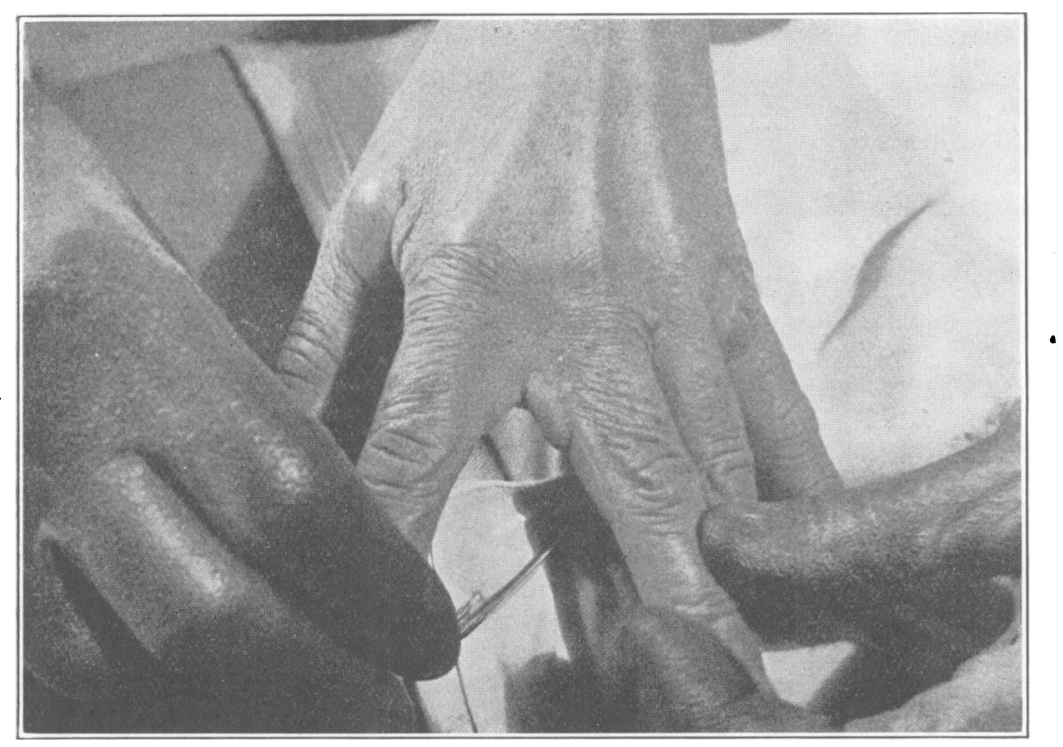

FIG. 6.

The diagnosis may not always be so easy as in this case. Fig. I3, p. 57, of my "Diagnosis and Treatment of Venereal Diseases in General Practice" illustrates the case of a Jew who was admitted to the Military Hospital,

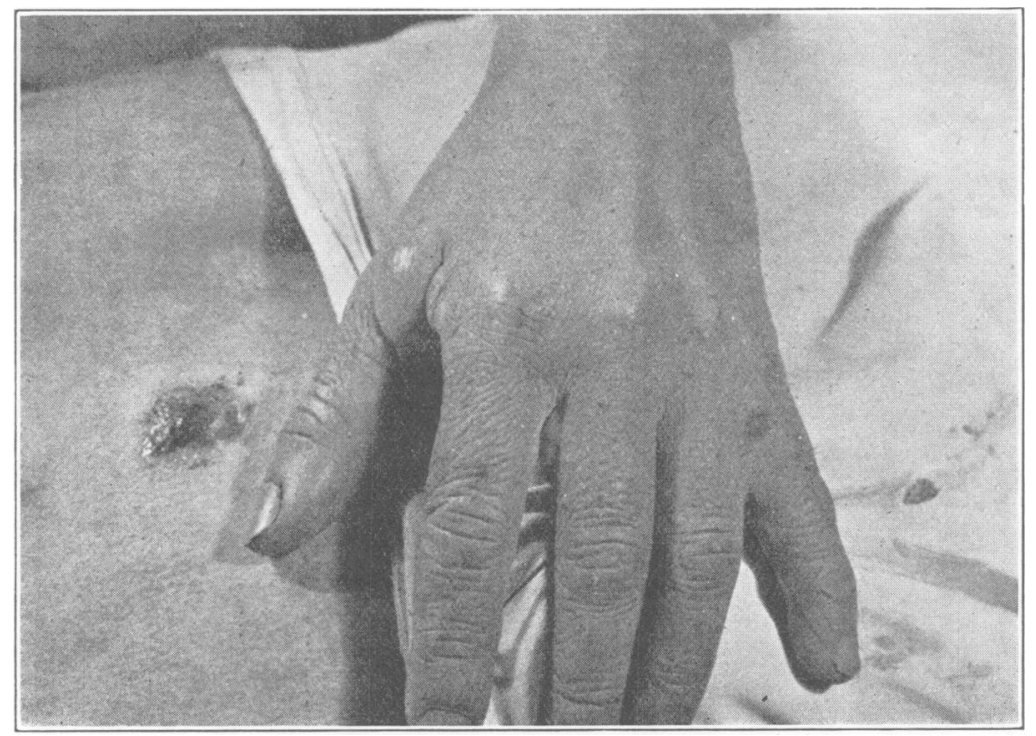

FIG. 7 .

$8 I$ 


\section{BRITISH JOURNAL OF VENEREAL DISEASES}

Rochester Row, during the war with a condylomatous condition of the scrotum, upper and inner sides of the thighs and between the buttocks. No bullæ were visible at first, and although the Wassermann and microscopical tests for syphilis gave negative results, it was thought for some time that the condition was syphilitic.

It is unnecessary to burden this note with the literature .on or a description of Pemphigus vegetans, since these can be found in any good work on skin diseases. 